\title{
Rancang Bangun Aplikasi Elektronik Resep yang Terhubung ke Kasir Menggunakan Website
}

\author{
Helfy Susilawati \\ Teknik Elektro \\ Universitas Garut \\ Garut, Indonesia \\ helfy.susilawati@uniga.ac.id
}

\author{
Tri Arif Wiharso \\ Teknik Elektro \\ Universitas Garut \\ Garut, Indonesia \\ triarif@uniga.ac.id
}

\author{
Teddy Mulyadi Hidayat \\ Teknik Elektro \\ Universitas Garut \\ Garut, Indonesia \\ teddy.mulyadi@uniga.ac.id
}

\begin{abstract}
A recipe is a description given by a doctor about a medicine and its dosage. Most health agencies use more manual prescriptions that are handwritten recipes. The most common weakness of manual recipes is the handwritten recipe which is difficult to understand. Most of the patients do not understand the doctor's writing, except the pharmacist. An electronic recipe is a recipe given by a doctor in the printed recipe of a recommended medicine. The purpose of electronic recipe is the recipe can be read clearly by the patient and also by the pharmacist. In addition, electronic recipe can also make it easier for patients to pay for medicines at the cashier. If in manual procedures the patient has to queue 2 times at the checkout, using an electronic prescription, the patient only needs to queue once at the cashier, which is when paying for medicine only. The method is used for this research is the Prototype method, and using website for its interface. From this research, the results show that the application built on the website is $100 \%$ well run and usable. This percentage result is obtained based on a survey of respondents that have been conducted.
\end{abstract}

Keywords-Electronic Recipe, Cashier, Prototype, Website

Abstrak-Resep merupakan keterangan yang diberikan oleh dokter mengenai obat dan beserta takarannya. Kebanyakan instansi kesehatan lebih banyak menggunakan resep yang resep manual yaitu resep yang ditulis dengan tangan. Kelemahanyang paling umum dari resep manual adalah tulisan tangan resep yang sulit dimengerti. Hampir sebagian besar pasien tidak mengerti dengan tulisan dokter tersebut, terkecuali apoteker yang bertugas. Resep elektronik adalah resep obat yang diberikan oleh dokter dalam bentuk hasil print resep obat yang direkomendasikan. Hal ini bertujuan agar resep obat tersebut dapat terbaca jelas leh pasien dan juga oleh apoteker. Selain itu, resep elektronik juga dapat mempermudah pasien untuk membayar obat di kasir. Jika pada prosedur manual pasien harus mengantri 2 kali saat di kasir, dengan menggunakan resep elektronik maka pasien hanya perlu mengantri 1 kali di kasir yaitu saat membayar obat saja. Metode yang digunakan pada penelitian ini adalah metode Prototype yang mana website digunakan untuk interfacenya. Dari penelitian ini didapatkan hasil bahwasanya aplikasi yang dibangun dengan berbasis website $100 \%$ berjalan dengan baik dan dapat digunakan. Hasil persentase ini didapat berdasarkan survey dari responden yang telah dilakukan.

Keywords-Resep Elektronik, Kasir, Prototype, Website PENDAHULUAN

Resep yaitu keterangan dari dokter mengenai obat yang disertai dengan takarannya, yang harus dipakai oleh pasien dan dapat ditukarkan dengan obat di apotek [1]. Resep merupakan suatu permintaan tertulis dari dokter untuk apoteker, resep tersebut dapat berupa tulisan maupun elektronik untuk melakukan penyediaan obat dan memberikan obat bagi pasien sesuai dengan apa yang telah dokter instruksikan dan sesuai peraturan yang berlaku [2]. Saat ini, resep yang didapat dari dokter biasanya sulit terbaca oleh pasien, resep tersebut hanya bisa dibaca oleh apoteker. Penelitian yang dilakukan oleh Yogini Hariprasad Jan dkk, menunjukkan bahwa sistem peresepan manual memiliki error rata-rata $77,4 \%$, sedangkan elektronik resep hanya menghasilkan error rata-rata 4,8\%. Sebelum adanya elektronik resep, terdapat 1153 item yang kehilangan informasi penting, sedangkan setelah menggunakan eprescription hanya terdapat 9 item yang kehilangan informasi penting [3]. Resep elektronik adalah resep yang dibuat oleh dokter dimana resep tersebut merupakan hasil print dari resep yang telah diinputkan oleh dokter pada aplikasi yang telah dibangun sebelumnya. Aplikasi yang dibangun merupakan aplikasi yang berbasis website. Website dapat dijadikan salah satu tolak ukur dimana dapat meningkatkan komunikasi antara satu pihak dengan pihak lainnya. Proses mengembangkan komunikasi dengan pelanggan maka setiap perusahaan harus memanfaatkan internet melalui situs website [4]. Situs website merupakan situs yang paling nyaman dan menjadi salah satu penentu apakah akan mendaftar pada program atau tidak, sehingga website tersebut menjadi penting [5]. Salah satu penggunaan e-health adalah dengan menggunalan website sebagai resep elektronik. [6]. eHealth merupakan salah satu bentuk manfaat TIK di sektor kesehatan yang bertujuan untuk meningkatkan pelayanan kesehatan [7]. Pelayanan resep elektronik yang berbasis website dapat digabungkan dengan pelayanan lainnya di rumah sakit yang berbasis website, seperti pelayanan administrasi untuk pendaftaran. Hasil penelitian menunjukkan bahwa, meskipun terdapat perbedaan antar negara, situs web rumah sakit lebih berfungsi sebagai tempat penyimpanan informasi, menampilkan rincian kontak tradisional [8]. eHealth dapat digambarkan mengenai penggunaan TIK khususnya Internet untuk meningkatkan pelayanan perawatan kesehatan[9]. Salah satu pelayanan kesehatan yang menggunakan website diantaranya adalah penelitian yang berjudul An Assessment of Radiology Residency Program Websites [10]. Dari hasil penelitian tersebut didapat 
bahwasanya penggunaan website dapat dilakukan lagi dengan lebih luas.

Resep elektronik yang kemudian akan menghubungkan langsung ke kasir merupakan salah satu bentuk peningkatan pelayanan kesehatan dikarenakan pasien hanya perlu menunggu satu kali untuk membayar ke kasir. Saat ini yang biasa dilakukan adalah pasien memberikan resep ke kasir, kemudian menunggu jumlah yang harus dibayar, kemudian membayar ke kasir. Sedangkan dengan menggunakan elektronik resep yang terhubung langsung ke kasir, pasien hanya perlu untuk menunggu nomor paien atau nomor antriannya dipanggil kemudian langsung membayar obatnya. Salah satu penelitian yang berhubungan dengan resep elektronik adalah penelitian yang dilakukan oleh Juwita dkk. Penelitian ini menganalisa implementasi dari E-recipe dan factor yang dapat mempengaruhinya di RSUP Dr. Wahidin Sudirohusodo Makassar [11]. Hasil dari penelitian ini adalah SDM sebagai pelaksana sudah mencukupi namun dari segi fasilitas komputer yang belum mencukupi untuk mengimplementasikan E-Recipes serta aplikasi yang mendukung pelaksanaan E-Recipe harus dikembangkan, lembar resep manual harus dikerjakan dan masih tersedia mengembangkan penerapan Electronic Drug Control (EKPO), Electronic Medical Record (E- KPO), Sistem Pendukung Keputusan Klinis, dan koneksi ke hasil dukungan klinis, melakukan edukasi penggunaan ponsel pengganti komputer, melakukan pemantauan langsung ke seluruh ruangan, menghilangkan lembar resep manual. Dari hasil penelitian tersebut dapat dilihat bahwasanya saat ini ERecipe sudah mulai diterapkan hanya saja masih terpisahpisah antara satu unit dengan unit lain. Penelitian ini bertujuan untuk menggabungkan antara unit dokter dengan unit kasir dengan menggunakan resep elektronik.

Pada tahun 2018, Shidiq Arif Siwiantoko melakukan penelitian yang mengenao aplikasi Web pada sistem EKlinik. Penelitian tersebut menghasilkan aplikasi E-klinik yang dapat digunakan untuk manajemen data pasien, manajemen data dokter, manajemen data pembayaran, manajemen daftar periksa, manajemen data obat, serta untuk memudahkan manajemen nomor antrian [12]. Pada tahun 2019, Ahmed Saleh Kenawy, Victoria Kett melakukan penelitian mengenai resep elektronik yang dapat mengurangi error pada sebuah klinik. Hasil penelitian yang dilakukan adalah Terdapat 3512 laporan insiden yang ditinjau untuk kesalahan penulisan resep dalam tulisan tangan dan elektronik. Penggunaan sistem elektronik menyebabkan penurunan sebesar $2 \%$ dalam kesalahan peresepan. Resep elektronik mampu mengurangi kesalahan resep dan penyaluran penggunaan resep daripada resep dengan menggunakan tulisan tangan di Klinik rawat jalan Mesir. Diperlukan sistem yang lebih maju dan terpercaya agar memiliki efek yang lebih efisien pada kesalahan tingkat dan alur kerja farmasi [13]. Persamaan penelitian ini merupakan penelitian yang berhubungan dengan resep elektronik akan tetapi penelitian ini hanya mencakup pada resep elektronik saja tidak mencakup pada bagian kasir.

Roadmap penelitian berdasarkan penelitian-penelitian yang dilakukan sebelumnya dapat dilihat pada gambar 1.
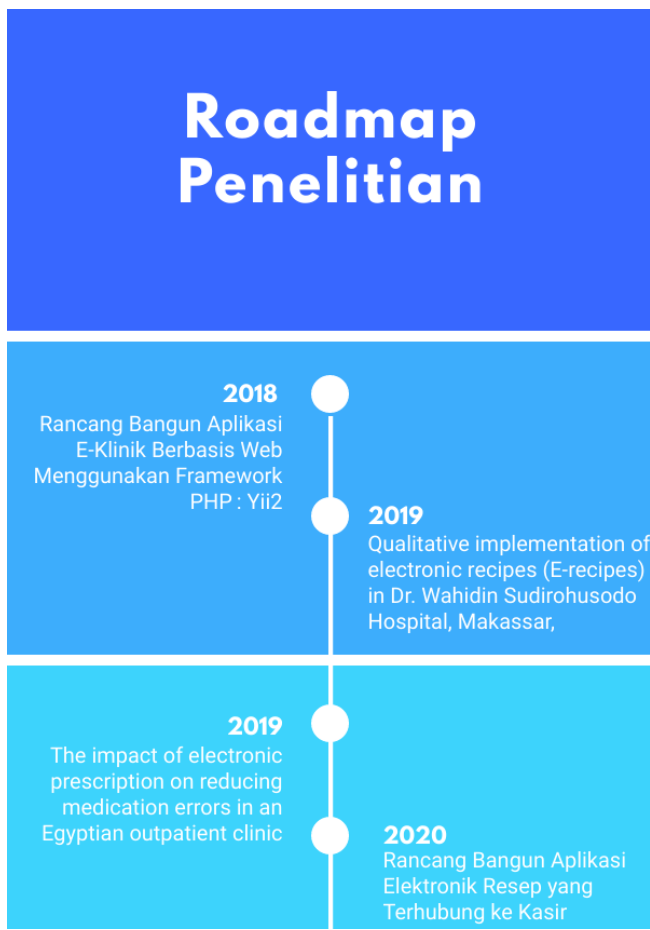

Gambar 1. Roadmap penelitian berdasarkan penelitian sebelumnya

Perbedaan penelitian yang dilakukan dengan penelitianpenelitian sebelumnya adalah sistem yang dibuat pada penelitian ini adalah sistem resep yang langsung dihubungkan ke kasir. Pada penelitian-penelitian sebelumnya, resep digital terhubung dengan apoteker tanpa terhubung dengan kasir. Dengan adanya penelitian ini, pasien dapat mengetahui terlebih dahulu mengenai harga yang harus dibayar untuk menebus obat-obat yang diresepkan. Hal ini tentu akan sangat membantu pasien dalam menentukan apakah biaya yang mereka sediakan cukup atau mereka harus mengambil dulu biaya tambahan.

\section{METODE PENELITIAN}

A. Metode Prototype

Metode pembuatan aplikasi ini dengan menggunakan metode prototype. Menurut Roger S Pressman, metode prototype dapat digunakan pada saat akan membangun suatu sistem. Metode ini sesuai untuk sebuah sistem atau perangkat yang akan dikembangkan kembali. Prototype akan berkembang sesuai dengan keinginan pengguna yang mana pada satu sisi juga akan membuat perkembangan bagi pengembang [14].

Proses pelaksanaan metode prototype dapat dilihat seperti gambar dibawah:

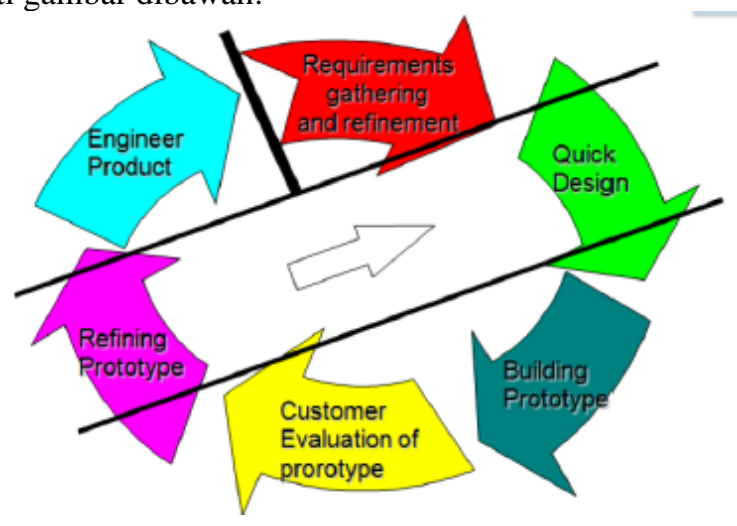

Gambar 2. Proses Prototype 
Berdasarkan gambar 1 proses prototyping adalah:

a. Pengumpulan kebutuhan

Pengembang dan pengguna akan bertemu untuk mendiskusikan apa yang akan dicapai dari sistem tersebut.

b. Perancangan

Pada proses prototype perancangan dilakukan dengan syarat mewakili semua aspek software yang diketahui, sehingga rancangan tersebut akan menjadi dasar pembuatan prototype.

c. Evaluasi Prototype

Pengguna akan mengevaluasi software untuk memutuskan apakah sistem yang sudah ada teah sesuai ekinginan atau tidak.

Tahap-tahap pengembangan Prototype model menurut Roger S. Pressman, Ph.D. adalah :

1. Mendengarkan pelanggan

Tahap ini dilakukan dengan cara mendengar keluhan dari pasien. Pada penelitian ini yang dimaksud dengan pelanggan adalah pasien, dokter, kasir, dan apoteker. Agar tercapai suatu sistem yang sesuai kebutuhan, maka sebelumnya harus diketahui terlebih dahulu bagaimana sistem yang sedang berjalan untuk mengetahui masalah yang terjadi.

2. Merancang dan Membuat Prototype

Perancangan dan pembuatan prototype sistem dilakukan pada tahap ini. Prototype yang dibuat harus menyesuaikan dengan kebutuhan sistem yang telah diketahui sebelumnya dari keluhan pelanggan atau pengguna.

3. Uji coba

Tahap ini merupakan tahap prototype yang telah dibangun diujikan pada pelanggan atau pengguna. Setelah hal tersebut dilakukan, kemudian dik=lakukan evalusi kekurangan yang mana hal tersebut akan menjadi pengembangan selanjutnya dari prototype yang ada.

\section{B. Black Box Testing}

Evaluasi aplikasi menggunakan BlackBox Testing. Blackbox testing bertujuan untuk memperlihatkan fungsi perangkat lunak tentang bagaimana cara pengoperasiannya, apakah input dan outpun sudah berjalan dengan baik [15]. Pada prosesnya Black Box Testing tidak memerlukan penggunaan ekspresi matematis sehingga tidak akan terjadi beberapa kali percobaan, yang hasilnya akan menghemat waktu dan uang. Pengaksesan jumalh titik dari input dan output memastikan kualitas dari sejulah model secara akurat dan sesuai [16]. Pengujian yang dilakukan dengan BackBox Testing kemudian dikonfirmasi kegunaannya dengan menggunakan 30 responden. Dimana responden tersebut yang memberikan penilaian apakah aplikasi berjalan dengan baik atau tidak.

\section{HASIL DAN PEMBAHASAN}

Sebelum melakukan penelitian, peneliti melakukan tes wawancara kepada pihak-pihak terkait, yakni dokter, kasir, dan juga apoteker. Berikut merupakan hasil wawancara dengan salah satu dokter yang bertugas di puskesmas.

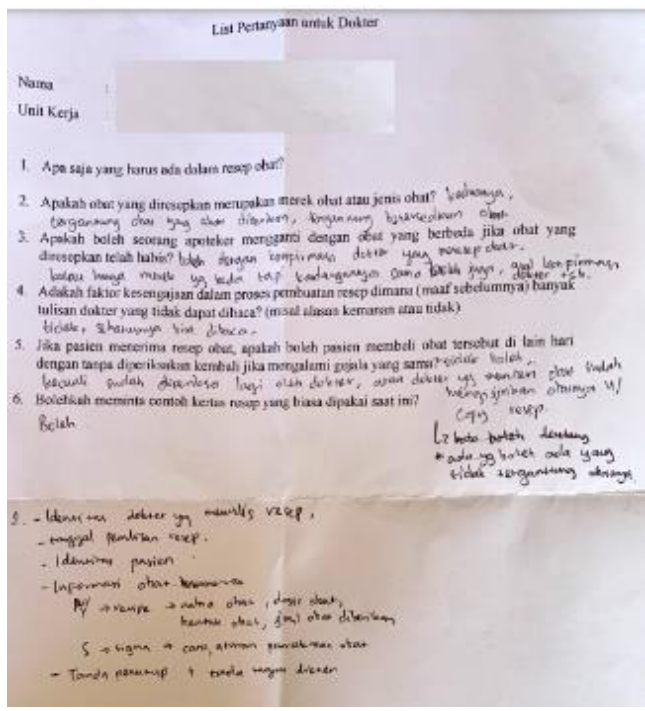

Gambar 3. Hasil wawancara dengan dokter

Gambar 3 adalah foto hasil wawancara dengan salah satu dokter di puskesmas. Data yang didapatkan dari dokter kemudian dijadikan acuan untuk membuat resep digital yang nantinya akan langsung dihubungkan ke kasir. Aplikasi ini dibangun dengan menggunakan website.

Berikut merupakan diagram UML yang dibuat untuk aplikasi.

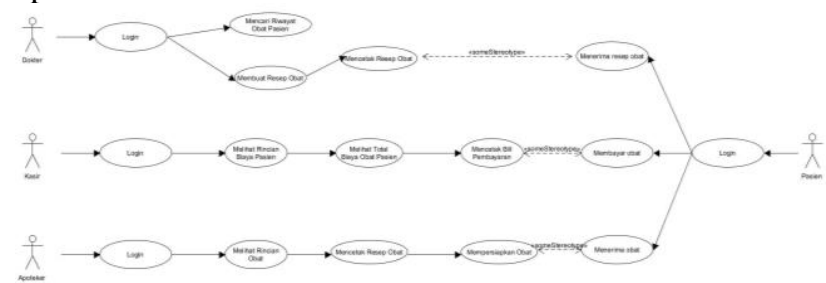

Gambar 4. Diagram UML

Gambar 4 menunjukkan diagram UML dari beberapa aktor yaitu dokter, apoteker, kasir, dan pasien. Dokter, apoteker, kasir, dan pasien dapat melakukan login di website yang telah dibuat. Dokter dapat melihat Riwayat obat pasien, membuat resep baru, dan mencetak resep. Kasir dapat melihat list pasien, melihat total yang harus dibayar pasien, dan mencetak bill untuk resep. Apoteker dapat melihat list pasien, melihat rincian obat, dan kemudian langsung menyiapkan obat tersebut. Pasien dapat menerima resep obat, yang mana pada resep tersebut sudah berisi rincian mengenai total biaya berikut dengan jumlah obat dan jenis obat yang diresepkan. Berikut screenshoot dari aplikasi yang telah dibuat.

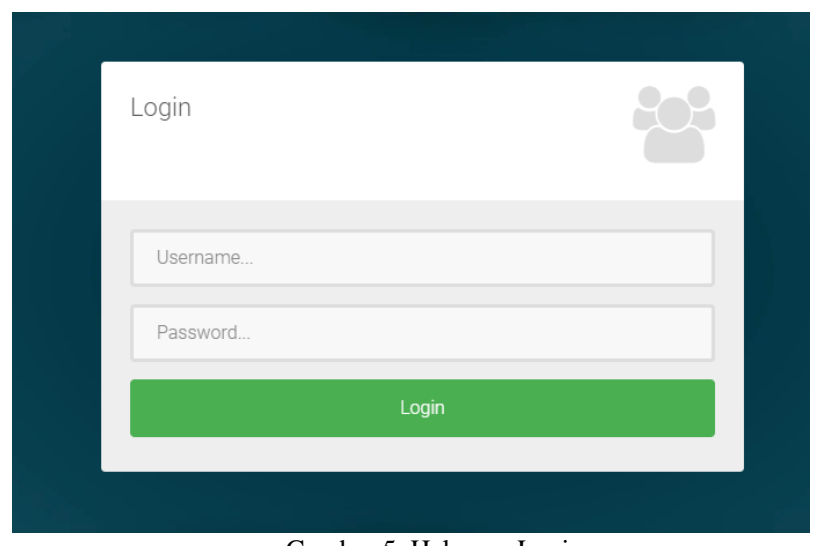

Gambar 5. Halaman Login 
Gambar 5 menunjukkan gambar login untuk aplikasi. Dalam penelitian ini, role untuk login dibagi menjadi 3 yaitu pasien, dokter dan kasir. Dokter dapat melakukan beberapa aktivitas diantaranya adalah melihat data pasien dan juga dapat melihat riwayat penyakit pasien.hal ini dilakukan agar dokter dapat mempertimbangkan jenis obat yang akan diberikan, apakah akan berdampak pada penyakit lainnya atau tidak. Pasien disini berfungsi untuk melihat catatan medisnya, sedangkan kasir berfungsi untuk mengecek resep yang masuk ke kasir dan berapa jumlah pembayaran yang harus dibayarkan oleh pasien.

\section{Selamat Datang Dokter Malika}

Form Resep Baru

Gambar 6. Halaman Dokter

Gambar 6 merupakan gambar halaman dokter. Halaman dokter dibuat minimalis agar sesuai dengan fungsinya. Di halaman dokter, dokter dapat mencari nama atau nomor pasien terlebih dahulu untuk melihat riwayat penyakit pasien. Dokter juga dapat menuliskan resep baru di halamannya. Hal ini dilakukan agar resep dapat dibuat menjadi digital dan dapat langsung diberikan ke kasir sehingga pasien hanya perlu 1 kali menunggu untuk membayar resep obat saja.

Selamat Datang Dokter Malika

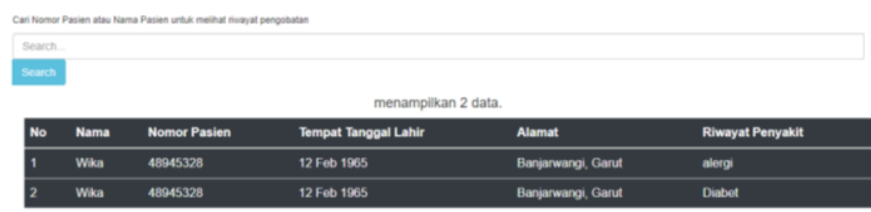

Gambar 7. Halaman Riwayat Pasien

Gambar 7 menunjukkan halaman riwayat pasien. Pada halaman ini yang diperlihatkan hanyalah data penting dari pasien seperti nomor pasien dan alamat pasien untuk mengklarifikasi jika ternyata terdapat pasien dengan nama yang sama. Riwayat penyakit pasien diperlihatkan untuk memberikan pertimbangan terhadap dokter pada saat akan memberikan resep obat.

Form Resep Baru

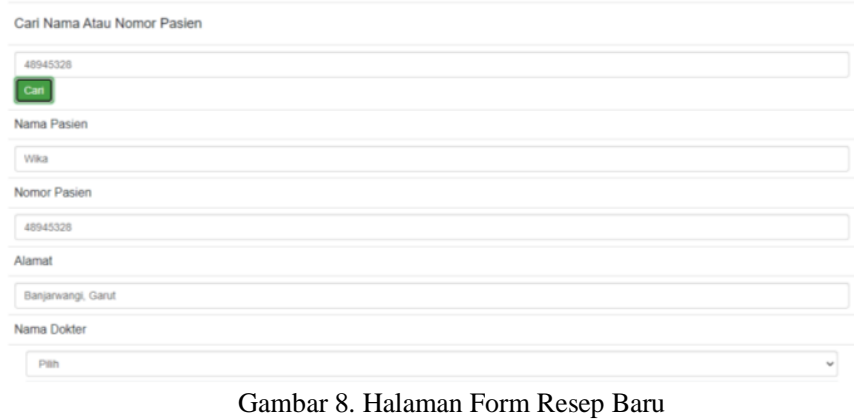

Gambar 8 merupakan halaman form resep baru. Dokter dapat mencari nama atau nomor pasien terlebih dahulu sehingga data umum pasien seperti nama, nomor dan alamat pasien akan tampil di kolom yang telah disediakan.

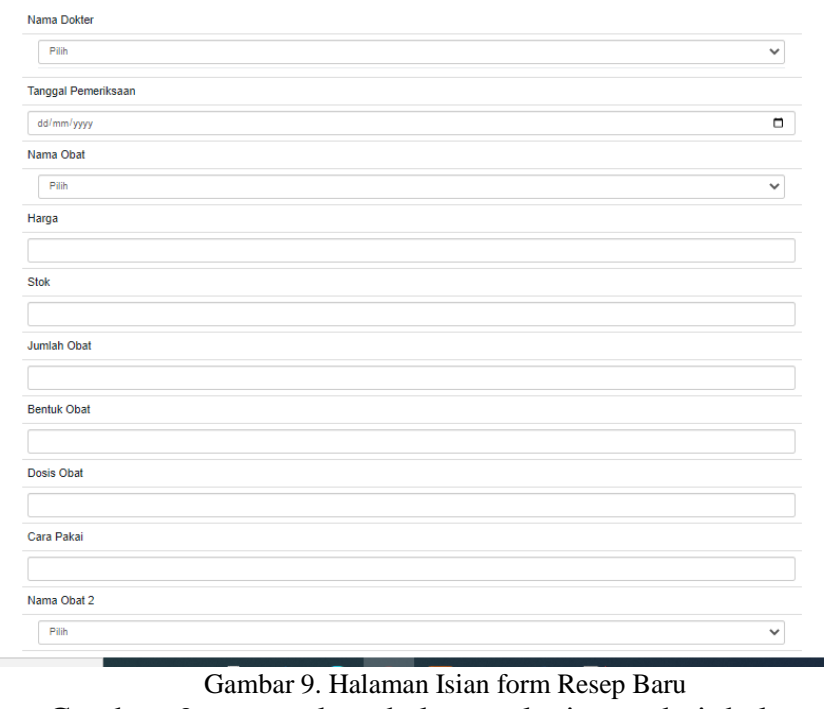

Gambar 9 merupakan halaman lanjutan dari halaman form resep baru yang mana pada halaman ini diisikan mengenai nama dokter yang menangani kemudian diisikan tanggal pemeriksaan, dan mencari nama obat dari kolom nama obat. Saat obat tersebut di klik maka akan muncul keterangan mengenai harga dan stok obat. Selanjutnya dokter hanya perlu mengisi jumlah obat, bentuk obat, dosis obat, dan cara pakai obat tersebut. Obat yang dapat dimasukkan saat ini maksimal 5 jenis obat dari 1 dokter dengan acuan dari wawancara yang telah dilakukan sebelumnya.

Halaman Detail Resep

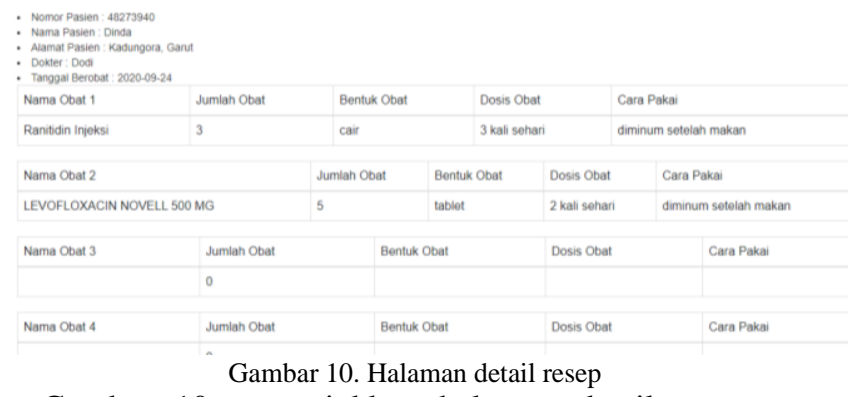

Gambar 10 menunjukkan halaman detail resep yang akan diterima oleh pasien, pada halaman ini akan terlihat detail resep yang diberikan oleh dokter beserta jumlah biaya yang harus dibayarkan oleh pasien untuk dapat menebus obat tersebut. Adanya kalkulasi biaya yang dapat ditemukan oleh pasien akan membuat pasien mempunyai persiapan untuk proses pembayaran. Total bayar yang harus dibayar oleh pasien adalah 515.000.

Hai Kasir

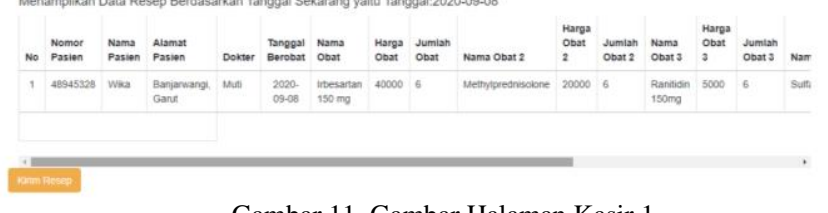

Gambar 11. Gambar Halaman Kasir 1 


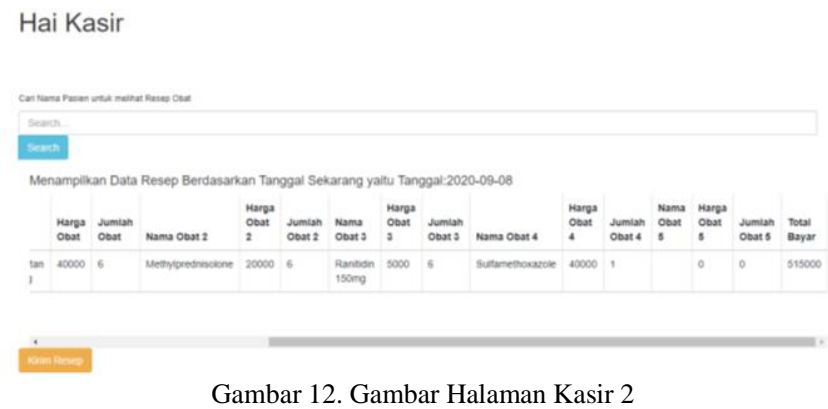

Gambar 11 dan 12 menunjukkan gambar halaman kasir. Halaman kasir hanya akan menunjukkan resep yang dating pada tanggal sekarang, sehingga data resep yang kemarin tidak akan tampil. Pada gambar 8 terlihat bahwa pasien bernama Wika dengan dokter yang memeriksanya bernama Muti. Jumlah obat yang diberikan oleh dokter sebanyak 4 jenis, dengan total bayar yang harus dibayar oleh pasien adalah 515.000.

Pengujian keberfungsian aplikasi dilakukan dengan cara survei pada 30 responden dengan menggunakan metode Black Box Testing. Hasil dari pengujian yang telah dilakukan dapat dilihat pada table 1 dibawah.

TABEL 1. Hasil Pengujian Black Box Testing

\begin{tabular}{|c|c|c|c|c|}
\hline No & $\begin{array}{l}\text { Kasus } \\
\text { yang } \\
\text { diuji }\end{array}$ & $\begin{array}{l}\text { Skenario } \\
\text { Uji }\end{array}$ & $\begin{array}{l}\text { Hasil yang } \\
\text { diinginkan }\end{array}$ & $\begin{array}{l}\text { Hasil } \\
\text { Peng } \\
\text { ujian }\end{array}$ \\
\hline 1 & $\begin{array}{l}\text { Halaman } \\
\text { Login }\end{array}$ & $\begin{array}{l}\text { Memasukkan } \\
\text { user dari } \\
\text { berbagai } \\
\text { role, misal } \\
\text { dokter atau } \\
\text { kasir } \\
\text { kemudian } \\
\text { diarahkan ke } \\
\text { halaman } \\
\text { masing- } \\
\text { masing. }\end{array}$ & $\begin{array}{l}\text { Saat } \\
\text { memasukkan } \\
\text { user dokter } \\
\text { dan di klik } \\
\text { button login, } \\
\text { maka } \\
\text { diarahkan ke } \\
\text { halaman } \\
\text { dokter, saat } \\
\text { memasukkan } \\
\text { user kasir, } \\
\text { maka ke } \\
\text { diarahkan ke } \\
\text { halaman kasir. }\end{array}$ & $\begin{array}{l}\text { Berf } \\
\text { ungsi }\end{array}$ \\
\hline 2 & $\begin{array}{l}\text { Mencari } \\
\text { riwayat } \\
\text { pasien }\end{array}$ & $\begin{array}{l}\text { Pada } \\
\text { halaman } \\
\text { dokter } \\
\text { terdapat } \\
\text { fungsi untuk } \\
\text { mencari } \\
\text { nama pasien } \\
\text { untuk } \\
\text { melihat } \\
\text { riwayat } \\
\text { penyakit dari } \\
\text { pasien. }\end{array}$ & $\begin{array}{l}\text { Saat } \\
\text { memasukkan } \\
\text { nama pasien } \\
\text { atau nomor } \\
\text { pasien } \\
\text { kemudian di } \\
\text { klik tombol } \\
\text { cari, maka } \\
\text { langsung } \\
\text { ditampilkan } \\
\text { data rigkas } \\
\text { mengenai } \\
\text { pasien } \\
\text { termasuk } \\
\text { riwayat } \\
\text { penyakit } \\
\text { pasien. }\end{array}$ & $\begin{array}{l}\square \\
\text { Berf } \\
\text { ungsi }\end{array}$ \\
\hline 3 & $\begin{array}{l}\text { Form } \\
\text { Membuat } \\
\text { resep } \\
\text { baru }\end{array}$ & $\begin{array}{l}\text { Pada } \\
\text { halaman } \\
\text { dokter dapat } \\
\text { membuat }\end{array}$ & $\begin{array}{l}\text { Form resep } \\
\text { baru } \\
\text { berfungsi, } \\
\text { yang mana }\end{array}$ & $\begin{array}{l}\square \\
\text { Berf } \\
\text { ungsi }\end{array}$ \\
\hline
\end{tabular}

\begin{tabular}{|c|c|c|c|c|}
\hline & & $\begin{array}{l}\text { resep baru } \\
\text { untuk pasien. }\end{array}$ & $\begin{array}{l}\text { pada saat } \\
\text { mencari } \\
\text { ringkasan } \\
\text { tentang pasien } \\
\text { dari tombol } \\
\text { search data } \\
\text { langsung ada, } \\
\text { kemudian } \\
\text { dokter } \\
\text { mengisi data } \\
\text { yang } \\
\text { diperlukan } \\
\text { mengenai } \\
\text { keterangan } \\
\text { obat. } \\
\text { Sedangkan } \\
\text { mengenai } \\
\text { nama obat } \\
\text { dokter dapat } \\
\text { langsung } \\
\text { mencarinya } \\
\text { dengan fitur } \\
\text { dropdown. }\end{array}$ & \\
\hline 4 & $\begin{array}{l}\text { Data } \\
\text { dapat } \\
\text { dilihat di } \\
\text { halaman } \\
\text { kasir }\end{array}$ & $\begin{array}{l}\text { Setelah } \\
\text { dokter } \\
\text { mengisi form } \\
\text { resep obat } \\
\text { untuk pasien, } \\
\text { maka data } \\
\text { tersebut } \\
\text { dapat terlihat } \\
\text { di halaman } \\
\text { kasir. }\end{array}$ & $\begin{array}{lr}\text { Di } & \text { halaman } \\
\text { kasir, data } \\
\text { resep dokter } \\
\text { dapat terlihat } \\
\text { dengan total } \\
\text { bayar yang } \\
\text { sudah } \\
\text { dikalkulasikan } \\
\text { di halaman } \\
\text { kasir. }\end{array}$ & $\begin{array}{l}\square \\
\text { Berf } \\
\text { ungsi }\end{array}$ \\
\hline
\end{tabular}

Williams menyatakan bahwa pengujian blackbox adalah pengujian yang mengabaikan mekanisme internal sistem atau komponen dan hanya berfokus pada output yang dihasilkan dalam menanggapi input yang dipilih dan kondisi eksekusi. Pengujian dengan menggunakan Black Box Testing hanya berfokus kepada hasil akhir dari software apakah dapat berfungsi dengan baik atau tidak, sehingga hasil pengujian dikategorikan hanya dalam dua kategori yaitu berfungsi atau tidak berfungsi. Berdasarkan data yang telah didapatkan (lihat table 1) diketahui bahwasanya kasus/yang diuji semuanya dapat berfungsi dengan baik.

Penelitian ini lebih menitikberatkan pada membangun aplikasi dan menganalisa pada aplikasi yang menghubungkan antara resep elektronik dengan kasir. Pada penelitian ini juga sudah dapat menghubungkan antara resep obat dengan jumlah yang harus dibayar oleh pasien pada saat akan menebus obat.

\section{KESIMPULAN DAN SARAN}

\section{A. Kesimpulan}

Berdasarkan hasil penelitian yang dilakukan, maka didapatkan kesimpulan bahwa penelitian ini menghasilkan keberfungsian software dengan seluruh scenario dapat dilakukan dengan baik. Dengan adanya aplikasi ini, maka pasien tidak perlu menunggu 2 kali untuk membayar, pasien hanya perlu menunggu 1 kali yaitu untuk proses membayar saja dengan adanya 
panggilan dari kasir. Estimasi waktu yang diperlukan untuk 1 pasien pada bagian kasir untuk menginputkan obat dan mencari harga obat kemudian menjumlahkan total obat sekitar 3-5 menit tergantung dari banyaknya obat yang diresepkan. Setelah membayar, pasien akan menunggu sekitar 1 menit untuk memperoleh bill pembayaran. Dengan menggunakan aplikasi ini, waktu 3-5 menit dapat disingkat menjadi 1-2 menit dikarenakan kasir sudah langsung mendapatkan kalkulasi dari jumlah obat yang diresepkan. Total waktu yang diperlukan di bagian kasir jika menggunakan metode manual sekitar 4-6 menit, sedangkan dengan menggunakan aplikasi adalah 2-3 menit untuk 1 orang pasien.

\section{B. Saran}

Proses pembayaran disini masih bersifat manual dalam artian membayar langsung ke loket. Untuk penelitian selanjutnya dapat dikembangkan untuk proses pembayaran melalui bank yang bisa diajak untuk Kerjasama agar proses pembayaran dapat dilakukan dengan tanpa menggunakan uang tunai.

\section{PENGHARGAAN}

Terima kasih kepada pihak-pihak yang terkait dalam penelitian ini yaitu Tri Arif Wiharso dan para responden. Tidak lupa untuk pihak Universitas yang telah membantu dalam proses pelaksanaannya.

\section{REFERENSI}

[1] Pusat Bahasa Kemdikbud, "Kamus Besar Bahasa Indonesia ( KBBI )," Kementeri. Pendidik. dan Budaya, 2016.

[2] Permenkes, Peraturan Menteri Kesehatan Republik Indonesia No 73 Tentang Standar Pelayanan Kefarmasian di Apotek. 2016.

[3] Y. H. Jani, M. A. Ghaleb, S. D. Marks, J. Cope, N. Barber, and I. C. K. Wong, "Electronic Prescribing Reduced Prescribing Errors in a Pediatric Renal Outpatient Clinic," J. Pediatr., 2008, doi: 10.1016/j.jpeds.2007.09.046.

[4] L. Hakim and L. Deswindi, "Assessing the Effects of eservicescape on Customer Intention: A Study on the Hospital Websites in South Jakarta," Procedia - Soc. Behav. Sci., vol. 169, no. August 2014, pp. 227-239, 2015, doi: 10.1016/j.sbspro.2015.01.306.

[5] F. M. Hall and M. L. Janower, "The new requirements and testing for American Board of Radiology certification: A contrary opinion," Radiology, vol. 248, no. 3, pp. 710-712, 2008, doi: 10.1148/radiol.2483080860.

[6] E. Ramadhani, "Desain E- Health : Sistem Keamanan Aplikasi Ehealth Berbasis Cloud Computing Menggunakan Metode Single Sign On," Semin. Nas. Inform. Medis, 2015.

[7] Menkes RI, "Keputusan Menteri Kesehatan Republik Indonesia Nomor 192/menkes/sk/vi/2012 tentang," vol. 2008, pp. 4-72, 2012.

[8] M. P. Bach, S. Seljan, B. Jaković, A. Buljan, and J. Zoroja, "Hospital Websites: From the Information Repository to Interactive Channel," 2019, doi: 10.1016/j.procs.2019.12.155.

[9] C. Pagliari et al., "What is eHealth (4): A scoping exercise to map the field," Journal of Medical Internet Research. 2005, doi: 10.2196/jmir.7.1.e9.

[10] D. R. Hansberry, J. Bornstein, N. Agarwal, K. E. McClure, S. P. Deshmukh, and S. Long, "An Assessment of Radiology Residency Program Websites," J. Am. Coll. Radiol., vol. 15, no. 4, pp. 663-666, 2018, doi: 10.1016/j.jacr.2017.11.010.

[11] Juwita, F. Rivai, and Ansariadi, "Qualitative study on implementation of electronic recipes (E-recipes) in Dr. Wahidin Sudirohusodo Hospital, Makassar," Enferm. Clin., 2020, doi: 10.1016/j.enfcli.2019.10.085.
[12] Y. Yudhanto and S. A. S. A. S. Siwiantoko, "Rancang Bangun Aplikasi E-Klinik Berbasis Web Menggunakan Framework PHP : Yii2," Indones. J. Appl. Informatics, 2019, doi: 10.20961/ijai.v3i1.31864.

[13] A. S. Kenawy and V. Kett, "The impact of electronic prescription on reducing medication errors in an Egyptian outpatient clinic," Int. J. Med. Inform., 2019, doi: 10.1016/j.ijmedinf.2019.04.005.

[14] R. S. Pressman, "Rekayasa perangkat lunak: pendekatan praktisi," Komput. - PERANGKAT LUNAK, Andi Publ., 2002.

[15] L. Linda, Pengujian Perangkat Lunak (Software Testing). 2015.

[16] R. Honarnezhad, M. Fathinia, and A. Khataee, "Mechanical production and sonocatalytic application of $\mathrm{Cu} 2 \mathrm{~S}$ nanoparticles for degradation of isopropylxanthic acid: Kinetic modeling via white and black box methods," J. Mol. Liq., 2019, doi: 10.1016/j.molliq.2019.110899. 